\title{
VENTAJAS DE LA MEDIACIÓN EN EL ÁMBITO SANITARIO Y SU AMPLIACIÓN A OTROS TÓPICOS*
}

\author{
ADVANTAGES OF MEDIATION IN THE HEALTH FIELD \\ AND ITS EXTENSION TO OTHER TOPICS
}

\author{
Carolina Riveros FerRADA** \\ Gabriela VILLARROEL TORO*** \\ Maximiliano OLIVARES RAMÍREZ ${ }^{* * * * *}$
}

RESUMEN: La Ley núm. 19.996, también conocida como Ley AUGE, consagró un régimen de garantías de salud y estableció, específicamente en su artículo 43, la mediación obligatoria para poder ejercer acciones de carácter indemnizatorias en contra de prestadores públicos y privados. Es muy interesante evaluar cómo ha funcionado la aplicación de la mediación obligatoria en el ámbito de la salud. Lo anterior, considerando que es un tema muy sensible entre la población y, en concreto, entre el personal de salud que ejerce su actividad, tanto en hospitales públicos como en clínicas privadas. También se evalúa si existen nuevas esferas donde la mediación pudiera ser considerada.

Palabras clave: salud, política social, negociación, pacientes, derechos civiles.
ABSTRACT: Law No. 19.996, also known as AUGE Lare, enshrined a system of health guarantees and, specifically in its Article 43, it established mandatory mediation prior to bringing any compensation action against either public or private providers. It is very interesting to evaluate how the application of mandatory mediation in the field of health has worked. The foregoing, considering that it is a very sensitive topic within the population and within the health personnel who work in public hospitals and private clinics. Likewise, we evaluate if there are new areas where mediation could be considered.

Keyzeords: Health, Public Policy, Negotiation, Patients, Civil Rights.

* Artículo recibido el 10 de octubre de 2017 y aceptado para su publicación el 10 de febrero de 2019. Este artículo de reflexión forma parte de la investigación Proyecto Anillo sobre "Mecanismos alternativos de resolución de conflictos como herramienta de modernización de la justicia. Construcción dogmática a partir de un análisis multidisciplinario", financiado por Conicyt (SOC 1406), Chile, del cual participa la doctora Carolina Riveros Ferrada en la calidad de coinvestigadora.

** ORCID: 0000-0001-8435-3206. Adscrita al Departamento de Derecho Privado y Ciencias del Derecho de la Facultad de Ciencias Jurídicas y Sociales de la Universidad de Talca, Chile.

*** ORCID: 0000-0002-3913-7966. Egresada de Derecho, Universidad de Talca, Chile.

***** ORCID: 0000-0003-2858-7299. Licenciado en Ciencias Jurídicas y Sociales, Universidad de Talca, Chile.

Boletín Mexicano de Derecho Comparado, nueva serie, año LI, núm. 155, mayo-agosto de 2019, pp. 997-1014. 
SUMARIO: I. Introducción. II. Mediación general. III. Mediación en un contexto global y nacional. IV. Mediación familiar en el ordenamiento jurídico chileno. V. Mediación obligatoria en el ámbito de la salud. VI. Realidad de la mediación en el ámbito sanitario. VII. ¿Ampliación de la mediación obligatoria en el ámbito sanitario? VIII. Conclusiones. IX. Bibliografia.

\section{INTRODUCGIÓN}

A propósito del proyecto Anillo SOC 1406 (Conicyt) "Mecanismos alternativos de resolución de conflictos", ha sido posible analizar con mayor detenimiento la mediación obligatoria en materia de salud. La relevancia del estudio es destacar el significado que conlleva la implementación previa y obligatoria de la mediación como un hito importante en el sistema de justicia estatal y sus múltiples beneficios (Esplugues, 2013; Palavecino, 2011), especialmente en el marco de los conflictos que puedan tener los pacientes a causa de diversas problemáticas que se llegan a producir en su atención de salud, o las consecuencias de la inexistencia de ella. El objetivo de este trabajo es estudiar y analizar con mayor profundidad la mediación en el ámbito sanitario chileno, considerando especialmente cómo ha operado en la realidad. La primera hipótesis del presente estudio es que el desconocimiento de la mediación y sus diversas consecuencias lleva a concluir erradamente que, por la inexistencia de acuerdos, la mediación como mecanismo de solución de conflictos es un fracaso. La segunda hipótesis es que la mediación previa y obligatoria en el ámbito de daños en salud desincentiva la judicialización de los conflictos.

Para poder analizar críticamente la implementación de la mediación en el ámbito sanitario se deben responder algunas cuestiones previas. ¿Por qué es relevante la mediación? ¿Cómo ha sido la implementación de la mediación en el ordenamiento jurídico nacional? ¿De qué manera se ha desarrollado la mediación en el ámbito sanitario? ¿Existirían posibilidades de aumentar el campo de aplicación de la mediación en el ámbito de salud? Éstas y otras interrogantes son el resultado del trabajo que se expone en las siguientes líneas. En tal sentido, se presentará la mediación desde su conceptualización, luego se explicará el ámbito de aplicación de la mediación en Europa y algunos países latinoamericanos. Posteriormente, se analizará la mediación familiar chilena como otro caso de mediación obligatoria;

Esta obra está bajo una Licencia Creative Commons

Atribución-NoComercial-SinDerivar 4.0 Internacional, IIJ-UNAM.

Boletín Mexicano de Derecho Comparado, núm. 155, mayo-agosto de 2019, pp. 997-1014. 
en seguida, se revisará la realidad de la mediación en el ámbito sanitario, y, finalmente, se estudiará la posibilidad de extender el ámbito de aplicación a otras temáticas.

\section{MEDIAGiÓN GENERAL}

Es sabido que respecto al acceso a la justicia y a los tribunales de justicia las críticas no son menores. "[L]a lentitud de los procesos, su excesivo formalismo y su carácter sobradamente adversarial se configuran como características de una justicia, anacrónica, despersonalizada y elitista" (Parra et al., 2018: 129). Por ello, la mediación surge como una herramienta que permite satisfacer las necesidades de los ciudadanos de una manera más democrática y efectiva (Parra et al., 2018: 129), incorporando con un rol protagónico a cada una de las partes del conflicto, permitiéndoles descubrir que la solución eficaz de un conflicto radica principalmente en la capacidad de cada cual en aportar a dicha solución (Gorjón, 2017: 111). De forma genérica, la mediación responde a un mecanismo alternativo de resolución de conflictos; el conflicto, a su vez, "tiene normalmente varios orígenes que giran en muchas ocasiones en torno a la percepción de la verdad que tiene cada una de las partes enfrentadas" (Rodrigues, 2017: 247). Es por ello que "la mediación se presenta, no sólo como un proceso de armonía a través del conflicto, sino también como el medio de establecer puentes entre el Estado y los ciudadanos" (Rodrigues, 2017: 249; Barona, 2011).

La mediación se puede definir como "un sistema para resolver conflictos entre dos o más personas y donde un tercero imparcial, llamado mediador, ayuda a que las partes puedan encontrar por sí mismas una solución al conflicto puntual" (Mediación Chile, n. d.), ${ }^{1}$ o bien, dicho de otra forma:

La mediación es un proceso de negociación de tipo colaborativo entre personas que mantienen una diferencia, facilitada por la intervención de un intermediario, quien recibe el nombre de mediador y es el encargado de guiar a las partes durante el proceso de negociación, escuchándolas y ayudándolas a alcanzar un acuerdo exitoso para todas ellas (Gómez, 1999: 385).

1 En torno a la efectividad de la mediación, específicamente respecto del acceso a la justicia y a la tutela judicial, véase Riveros et al (2018: 186-190).

Esta obra está bajo una Licencia Creative Commons Atribución-NoComercial-SinDerivar 4.0 Internacional, IIJ-UNAM. Boletín Mexicano de Derecho Comparado, núm. 155, mayo-agosto de 2019, pp. 997-1014. 
De lo anterior se puede desprender que las funciones de la mediación son amplias, y entre ellas están: la resolución y/o manejo de conflictos; la prevención de futuras controversias; la intervención de un mediador que actúa como un tercero imparcial, quien ayuda a las partes para que puedan encontrar por sí mismas una solución, entre otras.

Ahora bien, respecto a los objetivos centrales de la mediación, cabe destacar el modelo tradicional de la Escuela de Harvard, el cual señala los siguientes dos objetivos:

El primer objetivo central de la mediación es lograr el restablecimiento de la comunicación entre las personas conflictuadas, con el fin de promover una interacción colaborativa entre ellos que permita alcanzar acuerdos de solución de sus conflictos que sean satisfactorios para todas las partes.

$\mathrm{El}$ segundo objetivo, y como consecuencia de lo anterior, es aportar revalorización y más aceptación o reconocimiento interpersonal, esto es, del ser del otro y de sus particulares cosmovisiones e intereses. Basado en el respeto por el otro, su forma de ser, sus intereses y cosmovisiones particulares, y esperando para uno ese mismo respeto, la mediación pretende revalorizar el reconocimiento del otro y la tolerancia frente a la diferencia como base cultural para una actitud colaborativa frente a los conflictos (Gómez, 1999: 386).

Cabe señalar que este modelo, si bien se erige como uno de los más tradicionales, existen otros a destacar; por ejemplo, el modelo transformativo, el modelo circular y el esquema analítico, en virtud de los cuales, la utilización de éstos, "dependerá de cuál sea el objetivo específico que queramos alcanzar con la práctica del proceso de mediación” (Gómez, 1999: 386).

De lo expuesto, se puede indicar que la mediación se transforma en una "herramienta de responsabilidad y compromiso entre los mediados, en la cual sus razones, angustias y necesidades son atendidas consiguiendo un refuerzo del sentimiento de justicia y una aproximación de ésta a los ciudadanos" (Rodrigues, 2017: 250).

\section{MEDIACIÓN EN UN CONTEXTO GLOBAL Y NACIONAL}

Es interesante señalar que en el derecho comparado, y sobre todo en el derecho comunitario europeo, existe desde 2008 la Directiva 2008/52/CE

Esta obra está bajo una Licencia Creative Commons

Atribución-NoComercial-SinDerivar 4.0 Internacional, IIJ-UNAM.

Boletín Mexicano de Derecho Comparado, núm. 155, mayo-agosto de 2019, pp. 997-1014. 
del Parlamento Europeo y del Consejo, del 21 de mayo de 2008, sobre ciertos aspectos de la mediación en asuntos civiles y mercantiles. Lo que en definitiva, significó un impulso relevante y decisivo para la implementación de la mediación como un mecanismo alternativo de solución de controversias. Vale decir que a partir de dicha Directiva los distintos Estados que componen la Unión Europea han debido adaptar su normativa interna a esta Directiva. De modo ejemplar, Alemania publicó el 21 de julio de 2012 su Ley sobre Mediación. A su vez, en España se implementó el 6 de julio la Ley 5/2012; asimismo, en Francia la mediación se incorporó a través de la Ordenanza núm. 2011-1540.

De acuerdo con el artículo 3o. de la Directiva Europea, la mediación

$[\mathrm{E}] \mathrm{s}$ un procedimiento estructurado, sea cual sea su nombre o denominación, en el que dos o más partes en un litigio intentan voluntariamente alcanzar por sí mismas un acuerdo sobre la resolución de su litigio con la ayuda de un mediador. Este procedimiento puede ser iniciado por las partes, sugerido u ordenado por un órgano jurisdiccional o prescrito por el derecho de un Estado miembro.

A diferencia de otros ordenamientos latinoamericanos que ya cuentan con una normativa general relativa a la mediación, ${ }^{2}$ como por ejemplo Argentina con la Ley 24.537 que instituye la mediación prejudicial y obligatoria para una amplia gama de casos civiles y comerciales. Costa Rica posee la Ley de Resolución Alterna de Conflictos y Promoción de la Paz Social de 1998.

En particular, en Chile, la incorporación de la mediación se ha efectuado de manera inorgánica en diferentes disciplinas, careciendo de una regulación general. De este modo, considerando los diversos hitos respecto de las iniciativas en torno a la mediación, se puede indicar que lo primero corresponde al área del trabajo, en la cual, en 2001, se generó una Orden del Servicio núm. 1, del 30 de enero de 2002, que establece y regula la mediación a petición de parte y la de oficio. La mediación en materia laboral se reguló por medio de la Ley núm. 20.940 en los artículos 344, 351, 370 y 378 al 384 del Código del Trabajo. En 2004 se incorporó la mediación

2 En Argentina, la Ley 24.537 instituye la mediación prejudicial y es obligatoria para una amplia gama de casos civiles y comerciales (Álvarez, 2005: 32). En Costa Rica existe la Ley de Resolución Alterna de Conflictos y Promoción de la Paz Social, de 1998. 
familiar (Ley 19.968); luego, se integró la mediación en materia de daños por salud a través de la implementación de Unidades de Mediación del Consejo de Defensa del Estado (Ley 19.966 sobre Régimen de Garantías en Salud). Finalmente, han existido programas piloto en materia de mediación comunitaria o vecinal, en 2007 y 2008.

A continuación, se revisará la mediación familiar chilena como ejemplo de mediación obligatoria, y después se analizará críticamente la implementación que se ha efectuado sobre la mediación en el ámbito de salud. La Ley núm. 19.996 sobre el Régimen de Garantías Explícitas en Salud, publicada en el Diario Oficial el 3 de septiembre de 2004, también conocida como Ley AUGE, consagró un régimen de garantías de salud (Jordán, 2005: 99). Específicamente en su artículo 43, estableció la mediación obligatoria para poder ejercer acciones de carácter indemnizatorias, tanto en contra de prestadores públicos como privados. Con todo, antes de ello se revisará someramente la mediación familiar en Chile, debido a que es, en ciertas temáticas, obligatoria.

\section{MEDIACIÓN FAMILIAR EN EL ORDENAMIENTO JURÍDICO CHILENO}

En el ordenamiento jurídico chileno existen varios ejemplos de temáticas en las cuales la mediación es obligatoria; por ejemplo, en materia de derecho de familia, en los alimentos que se solicitan a los padres; en la temática de la relación directa y regular, entre otras.

Si nos remontamos a la historia de la Ley, la incorporación normativa de la mediación familiar se produce en 2004, luego de la aprobación de dos cuerpos legales: la Ley núm. 19.947 de Matrimonio Civil, y la Ley núm. 19.968 que crea los Tribunales de Familia. Respecto a los fundamentos para regular esta materia, de acuerdo con lo señalado en el mensaje del proyecto de Ley núm. 19.968, se indica que "el conflicto familiar es un conflicto que reclama soluciones cooperativas, es decir, soluciones que acrecienten el bienestar de todas las partes del conflicto; apuntando de esta manera a soluciones pacificadoras que favorezcan la armonía del grupo familiar". Del mensaje se puede desprender la necesidad jurídica que previó el legislador en materia de familia, en buscar alternativas a la resolución de conflictos (Cobas, 2014). 
Dentro de las ventajas de acceder a un proceso de mediación familiar destacan la rapidez, la confidencialidad, la igualdad entre las partes, el acuerdo es voluntario, es gratuito, entre otros. ${ }^{3}$

\section{MEDIACIÓN OBLIGATORIA EN EL ÁMBITO DE LA SALUD}

Respecto a la mediación en el ámbito de salud, cabe precisar que la salud es un derecho fundamental reconocido por nuestro ordenamiento jurídico (el chileno) y, por consiguiente, el Estado debe protegerlo, en esta línea, Gutiérrez (2008: 113) ha señalado que

Actualmente nos encontramos frente a un sistema de justicia que se encuentra prácticamente colapsado, lento y que en muchas ocasiones no logra satisfacer los intereses de quienes ponen en marcha estos mecanismos, se ha intentado, por diversas vías, buscar una forma de atender a ciertos reclamos de los particulares por vías alternativas a los tribunales de justicia, que intentan dar solución a los conflictos ocasionados, y que vulneran estos derechos.

Como se ha indicado de manera previa, la mediación es un mecanismo alternativo de solución de conflictos, en materia de salud en el ordenamiento jurídico chileno encontramos las siguientes normativas actualmente vigentes:

- Ley núm. 19.966 de 2004, que establece un régimen de garantías en salud, esta Ley se conoce como AUGE y dentro de su articulado se materializa y regula la mediación sanitaria. Importante es destacar que "esta Ley promueve la utilización de la mediación como un mecanismo de desjudicialización de conflictos por daños en salud, limitando los costes de indemnización y brindando a los afectados un acceso rápido a la justicia desde el Consejo de Defensa del Estado" (Hernández y Munuera, 2015: 53).

- Ley 19.880, que establece bases de los procedimientos administrativos que rigen los actos de los órganos de la administración del Estado.

3 A modo ejemplar, véase Correa Camus (2014); Vargas Pavez (2008); Alarcón Cañuta (n. d.) y Valdevenito (2013). 
- Decreto Supremo núm. 47 de 2005, que crea el Reglamento de Mediación por Reclamos en contra de Prestadores Institucionales Públicos de Salud o sus Funcionarios y Prestadores Privados de Salud, viene a complementar de manera más profunda la Ley núm. 19.966.

- Decreto Supremo núm. 35 de 2012, que aprueba el Reglamento sobre el Procedimiento de Reclamo, de la Ley núm. 20.584, que regula los derechos y deberes que tienen las personas en relación con acciones vinculadas a su atención en salud (Del Canto, 2014).

- Resolución núm. 142 exenta, de 2005, que establece montos máximos a pagar por los prestadores institucionales públicos en virtud del procedimiento de mediación establecido por la Ley núm. 19.966 .

Señalado lo anterior, podemos indicar que la mediación sanitaria, se encuentra definida en el artículo 43, inciso 3, de la Ley núm. 19.966 de 2004, como "un procedimiento no adversarial que tiene por objetivo propender a que, mediante la comunicación directa entre las partes y con intervención de un mediador, ellas lleguen a una solución extrajudicial de la controversia", la incorporación del artículo 43 a la Ley 19.966 implica la continuidad de una política pública en pos de mecanismos alternativos de solución de conflictos.

Respecto al procedimiento, el artículo 44 de la Ley núm. 19.966 regula que el interesado deberá presentar su reclamo ante el Consejo de Defensa del Estado, con indicación del nombre completo, cédula de identidad, edad, profesión u oficio, domicilio y demás antecedentes que permitan su identificación y la de su representante legal, en su caso.

En atención al plazo, señala la Ley en su artículo 45 que el plazo total para dicho procedimiento será de 60 días, corridos a partir del tercer día de la primera citación al reclamado, pudiendo dicho plazo, previo acuerdo de las partes, ser prorrogado hasta por 120 días, como máximo.

En torno a esta norma, es preciso indicar que es aplicable tanto al ámbito público como privado de la salud, y considera a todo profesional de la salud. Tiene por objetivo proteger al paciente cuando ellos mismos, o su entorno, han sido involucrados en hechos que producen un perjuicio o daños (Candia y Suazo, 2011: 300-303). En el caso de las atenciones en entes 
públicos la mediación está a cargo del Consejo de Defensa del Estado, y en el caso de las clínicas privadas, la mediación es efectuada por mediadores privados. Lo interesante de esta mediación de carácter prejudicial es que involucra a todos quienes son partícipes de la prestación de salud. No deja excluido a ningún profesional de la salud, por consiguiente, no se puede circunscribir sólo a la relación médico-paciente.

$\mathrm{Al}$ analizar la implementación de la mediación obligatoria, se puede observar - respecto de toda área donde la mediación es obligatoria - que existen una serie de detractores de la existencia de una mediación previa y obligatoria: en términos generales se indica que la mediación, en esencia, debiera ser voluntaria. Con todo, el hecho que la mediación sea prejudicial no significa para algunos autores que exista una obligación de llegar a un acuerdo, por ello, se desecha esta crítica. Es decir, sólo se obliga a participar en esta instancia, los resultados son abiertos y no quedan condicionados a la obligación de la participación (Salazar, 2016: 8-18). En tal sentido, cabe reiterar que con la incorporación de la mediación como obligatoria se busca promover formas alternativas de resolución de conflictos y para ello:

...se ha teniendo en cuenta: a) un mayor acceso a la justicia, pues se trata de vías más expeditas que los tribunales; $b$ ) la descongestión de tribunales que siempre padecen una alta carga de trabajo y el consecuente aumento en los tiempos de tramitación y costos; c) una mejor calidad de las decisiones producto de la participación directa de las partes en la resolución de su controversia, y $d$ ) la mayor eficiencia en la solución de algunos conflictos de menor entidad (Paredes, 2012: 192; Aguirrézabal, 2012; Ibáñez, 1996).

En favor de la mediación, específicamente en el ámbito sanitario, propone Carnero de Blas (2012: 17) que este método de solución alternativa de conflictos es idóneo en cuanto:

Las disputas que se pueden dar en las relaciones laborales de los profesionales del entorno sanitario, aquellas producidas por la convivencia de los pacientes en los que el dolor físico y/o psicológico caracteriza su estancia en estas instituciones, y las producidas entre los familiares y personas allegadas de los mismos, pueden ser solventados desde una vía pacífica y del entendimiento, que mejore la calidad de vida y de trabajo de todos aquellos individuos integrantes del sistema hospitalario. 
Los conflictos que puedan surgir a propósito de las acciones u omisiones en materia de salud son tremendamente relevantes para verificar la responsabilidad que se les pueda imputar a los profesionales de la salud y también a los prestadores de salud (Gutiérrez, 2008: 134).

Con respecto a las ventajas del proceso de mediación en salud, Varas (201 1: 245 y 246) indica las siguientes: la rapidez en la resolución del conflicto, la posibilidad de conversar directa y personalmente, buscar de manera conjunta una solución y mejorar la relación entre las partes. Si se llega a un acuerdo satisfactorio durante el proceso, las partes firman un Acta de Acuerdo en Mediación, que tiene el valor jurídico de un contrato de transacción, que indica las condiciones del acuerdo y su modalidad de cumplimiento.

Interesante resulta lo que plantea Hernández y Munuera (2015: 55) al indicar que la mediación sanitaria:

Abre un abanico de especialidades dependiendo del tipo de conflicto y la enfermedad que presenten las personas afectadas. Dando lugar a las siguientes especialidades en respuesta a los conflictos que se generan: mediación en la toma de decisiones sobre el tratamiento a seguir, etc.; mediación en organizaciones de salud, para resolver los conflictos internos entre profesionales o servicios; mediación en centros de atención primaria entre los enfermos, familias y profesional sanitario, entre otros.

\section{REALIDAD DE LA MEDIACIÓN EN EL ÁMBITO SANITARIO}

Si se analizan los estudios en este tema, no existe mucha literatura al respecto. Con todo, un estudio de Candia y Suazo (2011) que observa la tasa de éxito del sistema de mediación prejudicial por daños en salud en el periodo entre 2005 y 2009, ésta fue de $15.92 \%$. Las mediaciones efectuadas por el Consejo de Defensa del Estado tienen una tasa de éxito de 17.94\% mientras que los procedimientos realizados por mediadores privados tuvieron una tasa de éxito de $10.63 \%$. Si se analizan las cifras actuales del Consejo de Defensa del Estado el $21.1 \%$ son causas terminadas con acuerdo y $78.9 \%$ terminadas sin él durante 2005 y 2016, y se puede revisar en el siguiente cuadro extraído de los informes del Consejo de Defensa del Estado.

Esta obra está bajo una Licencia Creative Commons

Atribución-NoComercial-SinDerivar 4.0 Internacional, IIJ-UNAM.

Boletín Mexicano de Derecho Comparado, núm. 155, mayo-agosto de 2019, pp. 997-1014. 


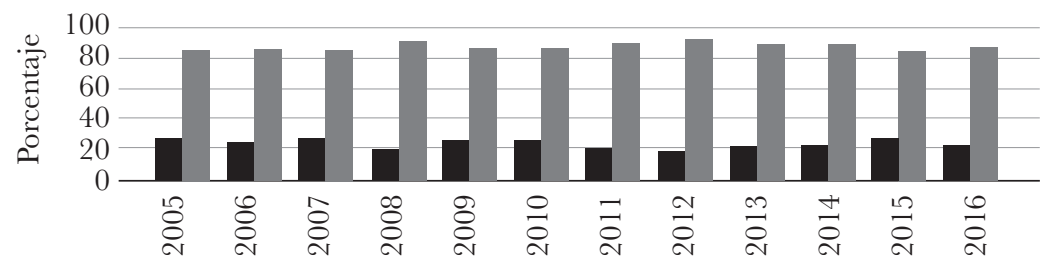

\begin{tabular}{|r|c|c|c|c|c|c|c|c|c|c|c|c|}
\cline { 2 - 12 } \multicolumn{1}{c|}{} & 2005 & 2006 & 2007 & 2008 & 2009 & 2010 & 2011 & 2012 & 2013 & 2014 & 2015 & 2016 \\
\hline $\mathbf{a}$ Con acuerdo & 24 & 22.4 & 23.7 & 18 & 23 & 23 & 18.9 & 17.1 & 20 & 20.4 & 24.8 & 21.7 \\
\hline Sin acuerdo & 76 & 77.6 & 76.3 & 82 & 77 & 77 & 81.1 & 82.9 & 80 & 79.6 & 75.2 & 78.3 \\
\hline
\end{tabular}

FuENTE: elaboración propia según datos del Consejo de Defensa del Estado de Chile.

En el cuadro 2 se puede observar en qué ámbitos de la atención en salud se solicita mediaciones.

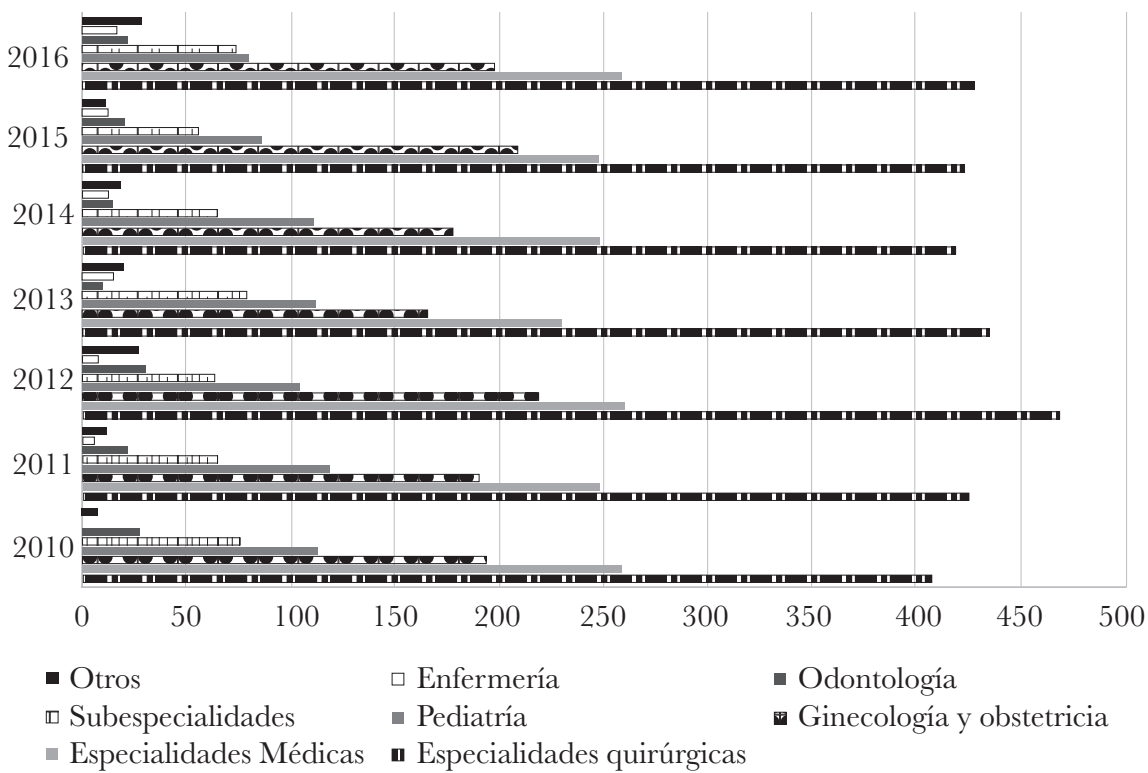

Fuente: Serie "Especialidades Médicas” Punto “2012”. Valor: 260.

La baja tasa de éxito en la mediación, a primera vista, podría indicar que el mecanismo de solución de conflictos es todo un fracaso, ya que me- 
nos del 20\% de las personas que asisten a mediación llegan a un acuerdo (Parra et al., 2018: 133). Sin embargo, hay que revisar el tema con mayor detenimiento, porque la falta de acuerdo en la mediación no necesariamente conlleva una acción ante los tribunales de justicia. Esta idea es la hipótesis central del estudio denominado "Mediación y desjudicialización en el Consejo de Defensa del Estado (CDE)" realizado por la Unidad de Estudios de dicha entidad estatal y presentado por Lagos (2013: 8), la hipótesis es la siguiente: "el proceso de mediación en salud ha contribuido a desincentivar el ejercicio de las acciones judiciales de carácter civil por parte de los reclamantes, que consideran haber sufrido daños con ocasión de una prestación de salud en establecimientos públicos, durante el periodo 2005-2011". Los resultados de dicho estudio arrojan que, de un total de 4,326 mediaciones terminadas, sólo 731 alcanzaron un acuerdo (16.89\%), lo que significa que renuncian a ejercer acciones de carácter civil. Hasta ahora se podría mantener la sensación de fracaso del sistema; sin embargo, de los restantes 3,595 casos que no lograron acuerdo, sólo 386 casos ejercen acciones jurisdiccionales, es decir, acciones civiles. Ello representa $10.7 \%$ de las causas sin acuerdo, lo que también implica que al sumar los casos de acuerdo (731) y los de sin acuerdo $(3,209)$, se llega un total de 3,940 casos en los cuales no se han judicializado (Lagos, 2013: 10). Ello sin duda alguna tiene como una de sus causas directas haber sido parte del proceso de mediación.

Carnero de Blas (2012: 17) expresa en torno a la mediación lo siguiente: "La mediación debe mostrarse como una vía de gestión del conflicto, y una vía de prevención del mismo, dado que sus bases se instauran en la cultura del entendimiento y la solución pacífica de las problemáticas surgidas, que de manera inherente se producen en las relaciones interpersonales". Reafirma esta idea revisar cuáles son los tópicos por los que existen reparaciones, a saber: disculpas y/o explicaciones, y prestaciones asistenciales e indemnizaciones. Aunque en la mayoría de los casos hablar acerca de estos conflictos es un elemento vital, y en muchos casos disuasivo para el ejercicio de acciones judiciales.

Por lo tanto, es posible indicar que la mediación previa y obligatoria en el ámbito de daños en salud ha logrado el objetivo de desincentivar la judicialización de los conflictos. La pregunta que cabe hacerse es si la mediación podría extenderse a otros ámbitos de la salud.

Esta obra está bajo una Licencia Creative Commons

Atribución-NoComercial-SinDerivar 4.0 Internacional, IIJ-UNAM.

Boletín Mexicano de Derecho Comparado, núm. 155, mayo-agosto de 2019, pp. 997-1014. 


\section{VII. ¿AMPLIACIÓN DE LA MEDIACIÓN OBLIGATORIA EN EL ÁMBITO SANITARIO?}

En primer lugar, hay que indicar que los conflictos en salud pueden ser clasificados, según la proposición de Carnero de Blas (2012: 17) del siguiente modo:

Profesional: conflictos producidos por la discrepancia de funciones, organización y comunicación entre el personal sanitario y la limitación de recursos físicos y temporales de la institución hospitalaria y la demanda asistencial realizada.

Social: conflictos derivados de la convivencia entre pacientes y familiares en situación de ingreso.

Asistencial: conflictos producidos por la insuficiente y/o ineficaz comunicación entre los/las pacientes y el personal sanitario administrativo, además los producidos por la mala praxis médica.

Legal: conflictos derivados del desconocimiento de la legalidad en casos "excepcionales" (maltrato, violación, incapacidades, accidentes de tráfico, etcétera) y la inseguridad que ello conlleva en las actuaciones clínicas con repercusiones de tipo legal.

En esta clasificación, los conflictos regulados por la Ley núm. 19.966 quedarían incorporados al grupo de los conflictos asistenciales y legales, en tanto el conflicto sanitario a resolver por la instancia de mediación comprende los daños causados en el cumplimiento de sus funciones de otorgamiento de prestaciones de carácter asistencial, sean ellas efectuadas por prestadores institucionales públicos o por prestadores de carácter privado. Entonces, la pregunta que se formula en líneas anteriores en cuanto al nuevo espacio que podría tener la mediación en objetos diferentes a los daños es, al menos, discutible en el ámbito profesional y social. En el ámbito profesional, es preciso discutir si el mecanismo de la mediación es adecuado para la solución de conflictos, debido a que en el mundo sanitario interactúan diversos profesionales de la salud, con formaciones profesionales diversas y con identidades diferentes, así, por ejemplo, kinesiólogos, enfermeras, terapeutas ocupacionales, nutricionistas/nutriólogo, matronas/ obstetras, médicos con diferentes especialidades, ingenieros, administrativos, entre otros.

La incorporación del ámbito social tiene relación con los conflictos que se suscitan en la realidad familiar, las diferencias que pueden darse en 
razón de tratamientos médicos que no son aceptados por el paciente y dicha decisión conflictúa a la familia del paciente, tratamientos médicos que son rechazados por causas religiosas, etcétera. En este sentido vale la pena considerar los derechos de los pacientes menores de edad que pueden caer en conflicto con sus padres o con el Estado; por ejemplo, aquellos padres que no desean vacunar a sus hijos.

Asimismo, es preciso tener presente los derechos de las personas mayores en torno a la salud (Munduate, 2005). Existe un sinnúmero de conflictos que pueden generarse en razón de materias que no han sido resueltas, cabe precisar que Chile envejece a pasos acelerados y que la población de adultos mayores es cada vez mayor. Por lo mismo, podría ocurrir que el paciente adulto mayor haya comunicado su voluntad respecto de determinados acontecimientos al médico tratante, o a su cuidadora o cuidador, pero no han sido comunicados a sus parientes más cercanos. La situación descrita puede significar un grave conflicto entre el personal sanitario y la familia, que podría incluso entorpecer el bienestar del paciente, en este caso de la persona mayor. En el caso de Chile se publicó, el 7 de octubre de 2017, la Convención Interamericana sobre la Protección de los Derechos Humanos de las Personas Mayores, por ello en la actualidad el tema cobra mucha relevancia.

En síntesis, la posibilidad de ampliar el ámbito de aplicación de la mediación como un mecanismo de solución de conflictos en el ámbito sanitario es altamente recomendable.

Reforzando las razones para ampliar a otros ámbitos la mediación en salud es posible indicar que

...su utilización permite la participación directa de los involucrados en el problema y la configuración conjunta de la solución, lo que genera el desarrollo de un sentimiento de satisfacción y aumenta las probabilidades de cumplimiento de los acuerdos alcanzados. Al ser partes directas del problema y gestores de su solución, las personas estarán más propensas a realizar cabalmente lo que hayan acordado (Riveros et al., 2018: 189).

\section{CONCLUSIONES}

1) La utilización de la mediación como mecanismo de solución de controversias es un fenómeno global, impulsado altamente en Europa por la Directiva 2008/52/CE del Parlamento Europeo y del 
Consejo, del 21 de mayo de 2008, sobre ciertos aspectos de la mediación en asuntos civiles y mercantiles.

2) En Chile, la mediación ha sido incorporada al ordenamiento de forma inorgánica. Con todo, existen áreas donde la mediación ha sido muy novedosa. Un ejemplo de ello es la mediación en el ámbito de salud, relativa a las prestaciones que pudieran generar daños realizadas por cualquier profesional ligado al área sanitaria, tanto de prestadores públicos como privados.

3) De acuerdo con los estudios efectuados, pareciera a primera vista que la mediación no ha cumplido su objetivo, puesto que la tasa de éxito es bastante baja. Sin embargo, en una segunda mirada, la conclusión es diferente. Las personas que presentan acciones judiciales son menos del $12 \%$ y, por lo tanto, un objetivo esencial para incorporar a la mediación al ordenamiento jurídico nacional, es decir, desjudicializar los tribunales, se consagra a lo largo de los años de aplicación de este mecanismo alternativo, o si se prefiere se impone la cultura de la paz por sobre la del conflicto. La mediación no sólo debe ser analizada por el porcentaje de acuerdos logrados, sino que incluso su trascendencia en la sociedad deviene por instalar la comunicación frente al escalamiento de conflictos.

4) Finalmente, el éxito en la disminución de acciones judiciales permite, al menos, discutir en que otros ámbitos relacionados con la salud de las personas pudiera ser relevante y adecuado el mecanismo de la mediación para la solución de controversias; por un lado, respecto de relaciones profesionales en el ámbito de la salud, así como cuando existan grupos de personas vulnerables, como los menores de edad y adultos mayores.

\section{BIBLIOGRAFÍA}

AguirRÉZABAL, Maite, 2013, "Mediación previa obligatoria y acceso a la justicia en el proceso de familia", Revista Chilena de Derecho Privado, núm. 20.

Alarcón Cañuta, Miguel, n. d., "Conveniencia de la participación de los niños en el proceso de mediación”, Ars Boni et Aaequi, vol. 11, núm. 2. Álvarez, Gladys Stella, 2005, "Hacia un cambio de paradigma cultural en resolución alternativa de disputas: el modelo de la «mediación preju- 
dicial obligatoria, anexa o conectada con tribunales civiles y comerciales en Argentina». Diez años de experiencia", en VARGas Viancos, Juan Enrique y GORJón GÓMEZ, Francisco Javier (coords.), Arbitraje y mediación en las Américas, Santiago de Chile, Centro de Estudios de Justicia de las Américas. Disponible en: http://wrewe.corteidh.or.cr/tablas/24544.pdf.

BARONA, Silvia, 2011, "Las ADR en la justicia del siglo XXI, en especial la mediación", Revista de Derecho de la Universidad Católica del Norte, vol. 18, núm. 1.

Candia Tapia, Paola y Suazo Galdames, Iván, 2011, "Tasa de éxito del Sistema de Mediación Prejudicial por Daño en Salud en Chile entre los años 2005 y 2009", International fournal of Odontostomatology, vol. 5, núm. 3.

Carnero de Blas, María, 2012, "Mediando en salud: una propuesta de mediación sanitaria en hospitales", Revista de Mediación, vol. 5, núm. 10.

COBAS, María, 2014, "Mediación familiar. Algunas reflexiones sobre el tema", Revista Boliviana de Derecho, núm. 17.

Correa Camus, Paula, 2014, "La experiencia de la mediación familiar en Chile. Elementos para una política pública futura", Revista Chilena de Derecho y Ciencia Política, vol. 5, núm. 2.

Del Canto Huerta, Rodrigo, 2014, "El rol de la Superintendencia de Salud en la aplicación y cumplimiento de la Ley núm. 20.584", Cuadernos de Extensión Furídica de la Universidad de los Andes, Santiago de Chile, núm. 25.

ESPLUGUES, Carlos, 2013, "El régimen jurídico de la mediación civil y mercantil en conflictos transfronterizos en España tras la Ley 5/2012, del 6 de julio", Boletín Mexicano de Derecho Comparado, México, año 46, núm. 136.

GómEz, Paulina, 1999, "La mediación, una forma alternativa de resolución de conflictos: su naturaleza, esencia, características, estructura, ventajas y desventajas frente a la solución judicial", Revista de Derecho de la Universidad Católica de Valparaíso, Valparaíso, núm. 20.

GORJÓn, Francisco Javier, 2017, Mediación, su valor intangible y efectos operativos. Una visión integradora de los métodos alternos de solución de conflictos, México, Tirant lo Blanch.

GutiÉrRez ARAQUE, María José, 2008, "La mediación en salud y acceso a la justicia”, Revista de Derecho del Consejo de Defensa del Estado, núm. 20. 
Hernández Navarro, J. C. y Munuera Gómez, Ma. P., 2015, "Mediación: el camino de la resolución de conflictos en Sanidad Militar", Sanidad Militar, Madrid, vol. 71, núm. 1.

IBÁÑEZ, Perfecto (coord.), 1996, La justicia civil: ¿ ¿opción residual o alternativa posible?, corrupción y Estado de derecho. El papel de la jurisdicción, Madrid, Trotta.

JORDÁn DíAZ, Tomás, 2005, “La Ley núm. 19.966 que crea un Régimen General de Garantías en Salud: sinopsis y análisis desde la perspectiva de los derechos humanos", Anuario de Derechos Humanos de la Universidad de Chile, núm. 1.

Lagos OchOA, María Soledad, 2013, "Impacto de la mediación en la judicialización de conflictos jurídicamente relevantes: un análisis en base a la experiencia chilena de mediación por daños de salud", Revista de Estudios de la fusticia, núm. 18.

Mediación CHILE, n. d., "Mediación", Mediación de conflictos familiares: Sistema Nacional de Mediación Familiar. Disponible en: http://wrwremediacion chile.cl/sitioumed/trabajadores/, consultado el 14 de noviembre de 2018.

MÉndez, Claudio A., 2009, "Los recursos humanos de salud en Chile: el desafío pendiente de la reforma", Revista Panamericana de Salud Pública, vol. 26 , núm. 3.

Munduate, Lourdes y Medina, Francisco (coords.), 2005, Gestión del conflicto, negociación y mediación. Intervenciones de mediación, Madrid, Pirámide.

Palavecino, Adriana, 2011, "Calidad de la mediación familiar licitada: superando el modelo express", Revista Chilena de Derecho y Ciencia Política, núm. 2.

PAREDES, Alejandro, 2012, "La mediación familiar obligatoria: una crítica a la regulación y funcionamiento en Chile", Revista Chilena de Derecho y Ciencia Política, vol. 3, núm. 2.

PArra Sepúlveda, Darío et al., 2018, "La mediación en el ámbito de salud y su rol en la relación sanitaria", Revista de Derecho de la Universidad de Concepción, vol. 86, núm. 243.

Riveros, Carolina et al., 2018, "Mediación y personas mayores en Chile", Revista de la Facultad de Derecho, núm. 45.

RODRIGUES, Catarina, 2017, "La mediación. ¿Una respuesta al nuevo paradigma del derecho?", Revista de Derecho de la Universidad Católica del Uruguay, Montevideo, núm. 15. 
SAlAZAR PÉREZ, Mauricio, 2016, "A 10 años del sistema nacional de mediación familiar en Chile”, Revista Mediación Familiar Chilena, Santiago de Chile.

URriola, Carlos et al., 2016, "La reforma de salud chilena a diez años de su implementación", Salud Pública de México, vol. 58, núm. 5.

Valdevenito, Caterine, 2013, "Presencia de los niños y niñas en la mediación familiar en Chile", Rumbos TS, núm. 7.

VARAS, Jorge, 201 1, "Mediación en el ámbito sanitario", Revista Obstetricia y Ginecología-Hospital Santiago Oriente Dr. Luis Tisné Brousse, vol. 6, núm. 3.

VARGas PaVEz, Macarena, 2008, "Mediación obligatoria. Algunas razones para justificar su incorporación", Revista de Derecho (Valdivia), vol. XXI, núm. 2. 